\title{
ENTRADA LIBRE EN EL «COTO VEDADO»
}

\author{
Elías Díaz \\ Universidad Autónoma de Madrid
}

RESUMEN. El autor compara en este trabajo sus tesis a propósito de la obligación de la obediencia al Derecho en un Estado democrático con las sostenidas por Ernesto Garzón Valdés. Ambos comparten la tesis de que la ética puede ofrecer justificación no sólo para la desobediencia al Derecho, sino también para su obediencia. Sin embargo, discrepan a la hora de dar cuenta de la justificación de los límites a la obediencia al Derecho. Mientras que la teoría del coto vedado de Ernesto Garzón Valdés, desde lo que sería un enfoque negativo, habla de «límites» de la democracia y de la regla de las mayorías, el autor prefiere formularlos, desde un enfoque positivo, en términos de imperativos de coherencia con los mismos principios éticos y políticos que definen y justifican a la democracia.

Palabras clave: Ernesto Garzón Valdés, obediencia al Derecho, regla de las mayorías.

ABSTRACT. The author compares his own thesis on the obligation to obey the Law in a Democratic State with the same thesis as supported by Ernesto Garzón Valdés. Both share the thesis according to which ethics offers a justification for disobedience but also for obedience to the Law. However they disagree when dealing with the foundations to the limits of that obedience. Whereas Ernesto Garzón Valdés in his theory of the "off limits area» talks, from a negative approach, about the «limits» of Democracy and of the majority rule, the author rather undertakes a positive approach and formulates those limits in terms of a command of coherence with those ethical and political principles that define and justify Democracy.

Keywords: Ernesto Garzón Valdés, legal obedience, majority rule. 
stas breves páginas en homenaje al viejo y querido amigo, el colega iusfilósofo Ernesto GARZÓN VALDÉs, son sobre todo para dar — para darnos— «señales de vida», cosa que a nuestra edad (de los dos) no es de ninguna manera algo intranscendente. Unido a ello, tampoco es mal pretexto (en los dos sentidos de la palabra, con o sin guión intermedio) el que me proporciona como incentivo el propio GARZÓN VALDÉS con su escrito Algunas consideraciones acerca del deber de obediencia al Derecho según Elías Díaz. Ésta fue en efecto la destacada contribución suya a la obra colectiva que, en mi setenta cumpleaños, buenos amigos y colegas me dedicaron, bajo la dirección de los profesores Liborio L. HIERRO, Francisco J. LAPORTA y Alfonso Ruiz Miguel, con el título de Revisión de Elías Díaz, sus libros y sus críticos (Madrid: Centro de Estudios Políticos y Constitucionales, 2007).

En tal escrito aquél recupera y analiza ese ineludible tema con observaciones muy valiosas y atendibles en torno a lo que yo por mi parte había venido señalando en mi libro De la maldad estatal y la soberanía popular (publicado en 1984) especialmente en el capítulo II, 1 sobre «la obediencia al Derecho» en polémica con Felipe GONZÁLEZ VICÉN (con intervenciones también de otros eminentes éticos y filósofos del Derecho) y en el capítulo I, 4 sobre «libertad y criterio de las mayorías» para una teoría crítica de la legitimidad. Reconozco que mis posteriores aproximaciones o alusiones a tales cuestiones han ido, en lo fundamental, por la línea allí marcada como, por ejemplo, aparece asimismo en mi último libro Un itinerario intelectual. De filosofía jurídica y política (Madrid: Biblioteca Nueva, 2003). Así, pues, estas palabras mías de ahora lo serán en gran parte para reafirmarme en aquellas antiguas posiciones, puede que con algunas nuevas razones en pro de ellas. La verdad es que yo no hubiera vuelto otra vez sobre estas cuestiones si no hubiera sido por el nuevo escrito de aquél. De todos modos aprovecho para puntualizar aquí sobre aspectos en los que inciden más estas advertencias y críticas de Ernesto GARZÓN VALDÉs.

Comenzaré con satisfacción por recordar lo que nos une en el primero de esos temas: «Coincido plenamente con Elías — escribe Ernesto- cuando afirma que no existe asimetría conceptual entre obediencia y desobediencia de las normas jurídicas, al menos por lo que respecta a su justificación». Y transcribe el texto que yo proponía en aquella polémica con Felipe GONZÁLEZ VICÉN y que seguiría confirmando ahora: «La ética puede suministrar justificación tanto para la obediencia a unas normas jurídicas como para la desobediencia a otras (depende de su concordancia o discrepancia con respecto a la ética), es decir puede suministrar fundamento tanto para la obligación de obedecer como para la no obligación de no obedecer e, incluso, para la obligación de desobedecer». Hasta aquí mis palabras en aquel libro de 1984.

Ahora GARZÓN VALDÉS explicita más razones para esa simetría, con las cuales yo también concuerdo plenamente. Dice así: «Sostener que no existen razones éticas para justificar el deber jurídico de obediencia equivale a negar la posibilidad de coincidencia de contenido de normas jurídicas y morales. Esto es empíricamente falso. Pero, además, conviene tener en cuenta que la desobediencia es la negación interna de la obediencia, es decir que ambas se mueven en el mismo nivel normativo. Cuando se aducen razones éticas para justificar la desobediencia a una norma escrita lo que se afirma —aduce agudamente aquél — es que estas razones son más fuertes que las razones (también éticas) que podrían invocarse para la obediencia. Si se está dispuesto a aceptar razones 
éticas que justifiquen la desobediencia, no se entiende —concluye él, con mi firme y viejo aserto- por qué la obediencia no puede nunca estar éticamente justificada». El párrafo es largo pero merece — creo— su reproducción aquí, pensando que pueda servir también a los participantes, concordantes o discrepantes, en aquella antigua polémica (por ejemplo, Javier MugueRZA, Manuel AtIENZA o Eusebio FernÁNDEZ); con ello les incito a la lectura de este comentario de Ernesto a su amigo Elías en este libro colectivo de 2007 en el que, por lo demás, ellos mismos colaboran.

Por idénticas razones - como punto final de nuestro idilio intelectual en este temadoy también este otro válido argumento de GARZÓN VALDÉs: «La disidencia que la desobediencia expresa es una actitud parasitaria con respecto al consenso: su valor moral depende del disvalor del consenso. Es, además — señala aquél—, una actitud transitoria: la desobediencia pretende crear un estado de cosas moralmente superior a aquel en el que la desobediencia estaba justificada. Logrado este objetivo, parecería que el deber de obediencia estaría plenamente justificado. Sin embargo, ello contradiría las tesis de la no justificabilidad moral de la obediencia. Es decir que habría que concluir que la desobediencia conduce necesariamente a una situación moralmente injustificable frente a la cual existiría un deber moral de desobediencia que concluiría en una nueva situación moralmente injustificable. Conclusión —aduce con moral y psíquica justificación Ernesto GARZÓN- que no deja de provocarme una frustrante fatiga». La hago mía: ¿será suficiente — supongo que no- para los recalcitrantes desobedientes?

Pero la felicidad (de la concordia con Ernesto) no podía durar eternamente: «Hasta aquí — dice - mi acuerdo con Elías. Tengo, sin embargo, algunas dudas — añadecon respecto a la tesis según la cual el deber ser ético sería una "expresión originaria y última, a la vez, de la conciencia individual” ( (palabras mías en la p. 79 de ese libro de 1984). Lo que ocurre, sin embargo, es que yo también tendría dudas (las mismas que Ernesto) respecto de esa «tesis» si por «conciencia individual» se entendiera algo opuesto a lo que aduce con razón aquél al «recordar una vez más a KANT quien distinguió claramente entre la autolegislación que satisface las exigencias de universalidad y la que responde sólo a los intereses de cada cual». Puedo decir que no era esta última (la reducida a los intereses de cada cual) mi concepción de la «conciencia individual», ni en 1984 ni ahora —estoy tranquilo sobre ello_-, aunque cabe (no tengo ya tiempo para revisar con detalle mi viejo libro u otros posteriores papeles en torno a ello) que no siempre lo expresara entonces o ahora con la suficiencia nitidez o rotundidad. Es, creo, lo que yo quería decir, por ejemplo, en el párrafo de la p. 85 que también cita aquél sobre «las exigencias éticas de la conciencia individual»: o sea, no por igual cualquier conciencia individual, aunque a su vez cualquier conciencia individual valga lo que vale. En cualquier caso, concuerdo con aquél cuando afirma - no sin problematismos de otra índole- que los dictados de la conciencia individual «tienen que satisfacer el requisito de la universalidad». Hasta reenviaría aquí al capítulo I sobre la autonomía personal del reciente libro de Francisco LAPORTA sobre El imperio de la ley. Una visión actual (Madrid: Trotta, 2007). Como se ve, me resisto fieramente a romper el fructífero consenso con el gran Ernesto GARZÓN VALDÉS.

Sin embargo - icon harto dolor de mi corazón! — ahora lo voy a hacer una vez más en relación al segundo de los temas antes enunciados y que en mi libro de 1984 yo rotulaba (cap. I, 4) como «libertad y criterio de las mayorías». Me interroga así el viejo 
amigo uniéndolo al tema anterior: «Mis preguntas rezan: ¿qué criterios de corrección estaría dispuesto Elías a aceptar con respecto al carácter necesario del deber moral de obediencia al Derecho?». Y ahora la pregunta clave formulada en estos términos: ¿Quién marca los límites del respeto a las decisiones mayoritarias: la propia mayoría —insinúa Ernesto- a través de una especie de «autolimitación Ulises»? Mi respuesta es, como la de él, negativa. Desde el punto de vista moral no es la mayoría, tampoco la minoría, ni - como tal— un sólo individuo, quien marca esos «límites». Lo sería, raíz de esos «límites», algo común a todos ellos como es la autonomía personal y moral, o si se quiere la libertad.

Otra cosa habrá de ser el planteamiento estrictamente político, respecto de las decisiones mayoritarias del poder constituido desde la Constitución e, incluso, del poder constituyente, necesitado de mayorías mucho más amplias y cualificadas (más limitadas «moralmente», por tanto, las mayorías simples y absolutas). Gregorio PECES-BARBA en su último libro, La España civil (2005), se manifiesta con toda contundencia contra las actitudes dogmáticas de quienes (su referencia es la jerarquía católica española) sostienen que en el Parlamento no se pueden discutir (ni aprobar) ciertos temas y ciertas leyes por entenderse que son contrarios a la verdad por aquélla considerada como dogma intangible y como norma moral inmutable, eterna y natural. «En la actualidad — dice PECES BARBA- se trata de temas como el divorcio, la eutanasia, el aborto o el matrimonio entre homosexuales, pero en el siglo XIX lo eran, entre otros, el derecho de sindicación, el sufragio universal o la libertad de expresión y de conciencia [...] Pero eso no es posible — rechaza aquél—; no hay — dice desde esa perspectiva — cotos vedados, ni política ni jurídicamente, a la deliberación por mayorías que no sean los que están en normas superiores (principio de jerarquía) o en materias para las que no está habilitado el órgano que pretende deliberar (principio de competencia)».

Siempre teniendo en cuenta lo ocurrido en los inicios de la Alemania hitleriana en 1933 -Ernesto GARZÓN también lo hace ahora- escribía yo en ese libro de 1984, aquí tomado por él como referencia para la cuestión. Es preciso - creo- reproducir por extenso los pasajes pertinentes para así orientar mejor el problema (pp. 65-67): «Pero más allá de la discusión sobre los concretos ejemplos históricos, empíricos, que puedan aducirse, lo que en todo caso habría que subrayar para el tema que aquí se debate, no es tanto, claro está, el que no pueda acabarse así fácticamente con la democracia (intimidando o engañando) - también un golpe de fuerza puede hacerlo-, sino que no puede acabarse con la democracia y con la legitimidad democrática invocando precisamente la libertad, es decir la legitimidad democrática. Esto es del todo contradictorio con sus propios presupuestos: sin libertad no hay legitimidad democrática y, por consiguiente (lo que es aquí aún más importante), no puede alegar legitimidad democrática quien previamente ha suprimido o dañado gravemente la libertad para decidir y elegir; ni tampoco quien, aún habiendo tal vez llegado por esa vía al poder, suprimiera después las libertades básicas de, al menos, libertad de expresión crítica y de política participación en la designación periódica de nuevos legisladores y gobernantes. [...] Quien suprime antes o después la libertad no puede invocar que basa y justifica su poder, su decisión, en la legitimidad democrática y en la soberanía popular; no puede decir, por tanto, que la decisión democrática ha producido o fundamentado su tiránico régimen político $[. .$.$] ¿No se puede entonces destruir libremente la libertad? —seguía$ yo-. Uno mismo es posible que pueda hacerlo para sí mismo [...] Un pueblo, en cam- 
bio, no puede hacerlo. Y ello porque un pueblo es algo efectivamente en cambio, en constante cambio, donde nuevos miembros, nuevos hombres y mujeres, se suman continuamente incorporándose al colectivo anterior [...] Ni siquiera la decisión unánime de una sociedad en un momento concreto podría alegar esa justificación democrática para suprimir la libertad, para entregar y alienar todo ese pueblo y para siempre al famoso, omnipotente y despótico, o supuestamente bueno y benéfico, dictador».

Dicho todo esto —escrito hace más de veinte años— volvería al diálogo y a las discrepancias también hoy con Ernesto GARZÓN VALDÉS. En consecuencia con lo anterior, más que hablar directamente de «límites» o «limitaciones» de la democracia y de la regla de las mayorías - como él suele hacer invocando el famoso «coto vedado»yo (yendo, creo, a la raíz y al fundamento de todo ello) preferiría formularlo en términos, digamos, de exigencias coherentes o, mejor, de imperativos de coherencia con los mismos principios éticos y políticos que definen y justifican a la democracia. Y la raíz y el fundamento de esos principios éticos se expresa, a mi parecer, desde esas diferenciadas - pero no enfrentadas - categorías que son la conciencia individual exigente, la libertad responsable, la autonomía personal, la autonomía moral. Me temo desde ahí, que nuestras hipotéticas diferencias no sean sólo terminológicas, aunque estas tampoco sean despreciables. Conociendo y reconociendo bien a Ernesto GARZÓN VALDÉS, para nada me permitiría abusar constatando la existencia - pero existir, existen - de tantos y tan poderosos «limitadores» de las mayorías y del Estado democrático que, por el contrario, casi siempre se olvidan de «limitar» a sus dictaduras: por ejemplo, la jerarquía católica española, pero no sólo ella. Es bien cierto que los límites de estos (ya se han señalado) son de signo radicalmente opuesto a lo que aquél entiende por derechos humanos aunque los vea también como «límite» o, incluso, cuando señala que sólo «fuera del "coto vedado", rige el dominio de la mayoría». Sé con total seguridad que, en cambio, ambos coincidimos muy ampliamente (si no completamente) en ese elenco fundamental de derechos humanos que él prefiere designar (enfoque negativo) como «límites» a las mayorías y yo buscando su fuente de producción (enfoque positivo) como imperativos coherentes de la misma democracia.

Con ese fondo de caracteres éticos, políticos y jurídicos compartidos en nuestras filosofías (e, incluso, en nuestros talantes personales), no dejan de preocuparme y de suscitarme reservas algunas de las concretas derivaciones de sus propuestas. Yo las veo necesitadas de mayores y mejores precisiones y matizaciones. Así ocurre, por ejemplo, cuando escribe que «en asuntos morales es aconsejable dejar de lado cálculos numéricos». Bien, pero tras ese punto de vista moral (que puedo compartir aunque dicho de otro modo) aquél a reglón seguido pasa a refutar mi «tesis» sobre el primado moral de la libertad aduciendo - planos diferentes - el punto de vista empírico de lo sucedido en la Alemania hitleriana de 1933. También se comprenderán mis reservas —en concordancia con lo escrito aquí- cuando aquél afirma que «la génesis de la moralidad ciudadana hay que buscarla en el "coto vedado" y no al revés», sin explicitar más acerca de cómo (incluso por quién) se crea el tal coto. Y, sobre todo, cuando hablando en estos temas ético-políticos de la superioridad de la mayoría o de la minoría, concluye así: «Todo depende de la calidad moral de los integrantes de la mayoría o de la minoría». ¿No se aproxima esto en exceso a las «democracias» censitarias y/o elitistas? Yo diría más bien que todo depende de esa mayor o menor coherencia con los principios éticos y políticos que definen y justifican a la democracia, cuya raíz se sitúa en ese ya 
mencionado respeto de y para todos a la conciencia individual, a la libertad responsable, a la autonomía personal, a la autonomía moral, categorías — insisto- diferenciadas pero para nada en forzosa e insalvable oposición o incomunicación.

Pero ya que no podemos cambiar el mundo - se nos dice-, cambiemos al menos de conversación, es decir, de palabras: en tal caso, yo propondría que en el curso de ella hablásemos algo más en estos términos de libertades reales (que llevan a mayores igualdades) y de exigencias ético-políticas coherentes con la democracia y algo menos de «límites» $\mathrm{y}$ «cotos vedados» ante las decisiones de las mayorías (y de las minorías). Ya sé que el amigo Ernesto no se dejará, pero (liberal igualitario) sí estará feliz de instar —siempre lo ha hecho- a la libre entrada de discrepantes y discutidores en ese paraíso que es el «coto vedado». Dentro o fuera de él así al menos tendremos nuevos pretextos para seguir viéndonos, hablando y debatiendo sobre estas graves cuestiones y sobre otras muchas que también son interesantes y quizás hasta más divertidas. 